\title{
Uso e ocupação do solo de duas sub-bacias hidrográficas no município de Domingos Martins, estado do Espírito Santo
}

\author{
Tiago Oliveira de Aguilar ${ }^{1}$, Caio Henrique Ungarato Fiorese ${ }^{2 *}$
}

\begin{abstract}
Resumo
O objetivo do trabalho foi estudar o uso e ocupação das terras das bacias hidrográficas do Córrego dos Cavalos (BHCC) e do Córrego São Floriano (BHCSF), bem como propor sugestões para melhorias locais. Os procedimentos ocorreram no programa ArcMap, utilizando o GEOBASES/ES como base de dados cartográfica. Foram delimitadas as bacias gerando inicialmente o Modelo Digital de Elevação, obtendo a rede hidrográfica local. No GEOBASES/ES, foram adquiridos dois arquivos (shp) de uso de solo para o estado do Espírito Santo nos mapeamentos dos anos 2007-2008 e 20122015 para, posteriormente, delimitar as Áreas de Preservação Permanente (APP) e o estudo dessas bacias conforme a literatura. Há maior predominância de vegetação nativa, que apresentou redução na BHCC, sendo um fator preocupante. As culturas temporárias tiveram boa representatividade, e a macega apresentou crescimento, constituindo um problema quanto ao manejo do uso de solo. A silvicultura (eucalipto; pinus) apresentou crescimento, inclusive nas APPs, que sofreram redução da vegetação nativa, mas tiveram redução de pastagem. Medidas como implantação de agroflorestas em detrimento a monocultura, manejo adequado da silvicultura, agricultura e pastagem e educação ambiental são fundamentais. Para futuros estudos, analisar a evolução da silvicultura e monitorar os cursos hídricos.
\end{abstract}

Palavras-chave: Área de preservação permanente. Cobertura da terra. Geoprocessamento. Gestão territorial. Impactos ambientais.

\section{Land use and occupation of two hydrographic sub-basins in the municipality of Domingos Martins, state of Espírito Santo}

\begin{abstract}
The objective of this work was to study the use and occupation of the lands of the Cavalos Stream (BHCC) and São Floriano Stream (BHCSF) watersheds, as well as to suggest suggestions for local improvements. The procedures were performed in the ArcMap program, using GEOBASES/ES as a cartographic base. The basins were delimited, initially generating the Digital Elevation Model, obtaining the local hydrographic network. In GEOBASES/ES, they were acquired in two land use files (shp) for the state of Espírito Santo in the mappings of the years 2007-2008 and 20122015, to later define the Areas of Permanent Preservation (PPA) and study of these basins according to the literature. There is a greater predominance of native vegetation, which presented a reduction in BHCC, being a worrying factor. Temporal crops presented good representativeness and the macega presented growth, constituting a problem in the land use management. The silviculture (eucalyptus; pinus) presented growth, even in PPAs, which suffered reduction of native vegetation, but presented pasture reduction. Measures such as the implementation of agroforestry systems to the detriment of monoculture, proper management of forestry, agriculture and pasture, and environmental education are fundamental. For future studies, analyze the evolution of forestry and monitor watercourses.
\end{abstract}

Keywords: Permanent preservation area. Earth coverage. Geoprocessing. Territorial management. Environmental impacts.

\footnotetext{
${ }^{1}$ Instituto Federal do Espírito Santo, Alegre - ES. Brasil.

https://orcid.org/0000-0003-2341-3556

${ }^{2}$ Centro Universitário São Camilo, Cachoeiro de Itapemirim - ES. Brasil.

https://orcid.org/0000-0001-6866-0361

*Autor para correspondência: caiofiorese@hotmail.com
}

Recebido para publicação em 02 de novembro de 2019. Aceito para publicação em 10 de dezembro de 2019.

e-ISSN: 2447-6218 / ISSN: 2447-6218 / (C) 2009, Universidade Federal de Minas Gerais, Todos os direitos reservados. 


\section{Introdução}

Através do crescimento demográfico e da evolução tecnológica, foram intensificadas várias atividades antrópicas, causando modificações no espaço geográfico, resultadas de atitudes irracionais no que tange à ocupação de terras, gerando um processo de desequilíbrio ambiental (Lopes et al., 2016).

O uso e ocupação dos solos podem afetar diretamente a qualidade e disponibilidade dos recursos hídricos, em função da acelerada urbanização, supressão da vegetação nativa ou da agropecuária, sendo que os impactos ambientais negativos variam conforme o solo, nutrientes, contaminantes metálicos e transporte de sedimentos, por exemplo (Cornelli et al., 2016). Assim, alteram sensivelmente os processos físico-químicos e biológicos dos espaços naturais (Menezes et al., 2016).

Os impactos ambientais em bacias hidrográficas podem ser mitigados por meio do monitoramento do uso e cobertura do solo considerando informações espaço-temporais acerca das alterações na paisagem (Coelho et al., 2014). Dessa forma, estudos que objetivam diagnosticar as condições do ambiente natural e analisar a sua dinâmica, podem contribuir na gestão sustentável dessas regiões (Moraes et al., 2018).

De acordo com Chuerubim e Pavanin (2013), as bacias hidrográficas podem ser adotadas como unidades de planejamento, permitindo tomadas de ações conjuntas entre instituições de ensino, pesquisa e governos, beneficiando diretamente a população e o meio ambiente locais. Leal (2012) enfatiza a relevância dos estudos em nível de bacias hidrográficas na compatibilização do uso e ocupação de solo nessas regiões com a disponibilidade hídrica, sendo um meio de atingir a sustentabilidade econômica, social e ambiental. Já a adoção de unidades menores da bacia hidrográfica (as chamadas sub-bacias) facilita, por razões técnicas e estratégicas, o seu planejamento (Lopes et al., 2016).

O geoprocessamento é um importante conjunto de ferramentas capaz de reunir a cartografia e o armazenamento de dados, permitindo tratar e analisar as informações, de maneira integrada, por meio de programas computacionais relacionados a um Sistema de Informações Geográficas (SIG) (Sebusiani e Bettine, 2011) que, por sua vez, auxilia na produção de mapas para melhor compreensão da realidade e na divulgação dos resultados alcançados, podendo contribuir na resolução de problemas (Criado e Piroli, 2012). Pessoa et al. (2013) destacam que os mapas de uso de solo podem ser usados pelos órgãos públicos fiscalizadores, a fim de identificar áreas em conflito com uso de solo.

Diante da relevância da temática discutida e, com auxílio de geotecnologias, o objetivo deste estudo foi avaliar o uso e ocupação das terras das sub-bacias hidrográficas dos Córregos São Floriano e dos Cavalos, afluentes do rio Jucu Braço Sul (ES), como forma de subsidiar melhorias nas áreas estudadas em termos de conservação dos solos e gestão territorial.

\section{Materiais e Métodos}

Os locais de estudo foram a sub-bacia hidrográfica do Córrego dos Cavalos (sigla - BHCC) e a sub-bacia hidrográfica do Córrego São Floriano (sigla - BHCSF). Ambas são localizadas no município de Domingos Martins, na região Serrana do estado do Espírito Santo, e fazem parte da bacia hidrográfica do rio Jucu Braço Sul e são de grande importância para a região do referido estado, pois é um dos principais mananciais que abastecem a Região Metropolitana da Grande Vitória, além de garantir boa parte da energia elétrica produzida no estado do Espírito Santo. O clima na região é Aw, de acordo com a classificação de Köppen, ou seja, tropical úmido com estação seca no inverno e chuvosa no verão (Alvares et al., 2013). A Figura 1 mostra a localização da região estudada.

A base de dados utilizada foi o Sistema Integrado de Bases Geoespaciais do Estado do Espírito Santo (GEOBASES), que forneceu arquivos, em formato shapefile (shp), acerca das curvas de nível da região em estudo. Os procedimentos foram executados no programa ArcMap, na versão 10.2.2, para delimitação das bacias hidrográficas. Tendo adicionados os arquivos adquiridos no GEOBASES, foi gerado um Modelo Digital de Elevação (MDE) da área. Com auxílio do Arc ToolBox, foi, a princípio, corrigido o MDE gerado, a fim de preencher as depressões que podem "interromper" o fluxo d'água da drenagem local e preparar o banco de dados necessário para as etapas posteriores. Em seguida, foram delimitados, respectivamente, a direção (flow direction) e o acumulado (flow accumulation) da drenagem da região. Para vetorizar os canais de drenagem traçados, foi utilizado o recurso com, da tabela de ferramentas, utilizando um valor com boa precisão para o fluxo de drenagem. Valores muito ou pouco precisos trazem resultados exorbitantes, fugindo, assim, da realidade mais próxima. Assim, foi possível gerar a rede hidrográfica da região.

Para delimitar as sub-bacias hidrográficas estudadas, foram demarcados dois pontos (para cada bacia) mais próximos aos exutórios, no rio Jucu Braço Sul para, adiante, o uso da ferramenta watershed. Com isso, foram geradas as duas sub-bacias hidrográficas, convertidas, posteriormente, em polígono (formato shapefile).

Ainda com auxílio do GEOBASES, foram adquiridos dois arquivos acerca do uso e ocupação de solo para todo o estado do Espírito Santo, em mapeamentos realizados nos anos de 2007 a 2008 e 2012 a 2015, ambos feitos em escala igual a 1:25000 e resolução espacial de 0,25 m e $1 \mathrm{~m}$, respectivamente. Em layout do ArcMap, com auxílio do recurso clip, os arquivos de uso 
de solo foram recortados, delimitando, assim, o uso e ocupação de solo apenas para cada sub-bacia estudada. A identificação e quantificação das classes foram feitas através do recurso summarize, da tabela de atributos dos arquivos gerados e da aba symbology, além da conversão dos dados numéricos do ArcMap para formato aceito pelo Microsoft Excel. Assim, foi possível estimar o percentual e a área de cada classe de uso de solo. Para auxiliar na interpretação dos resultados, em consonância com a literatura considerada, foram elaborados quatro mapas (sendo dois para cada sub-bacia hidrográfica e um para cada período do mapeamento feito pelo GEOBASES), permitindo a realização de estudos relacionados à distribuição das classes de uso e ocupação das terras.

Figura 1 - Localização das sub-bacias hidrográficas do Córrego São Floriano e do Córrego dos Cavalos

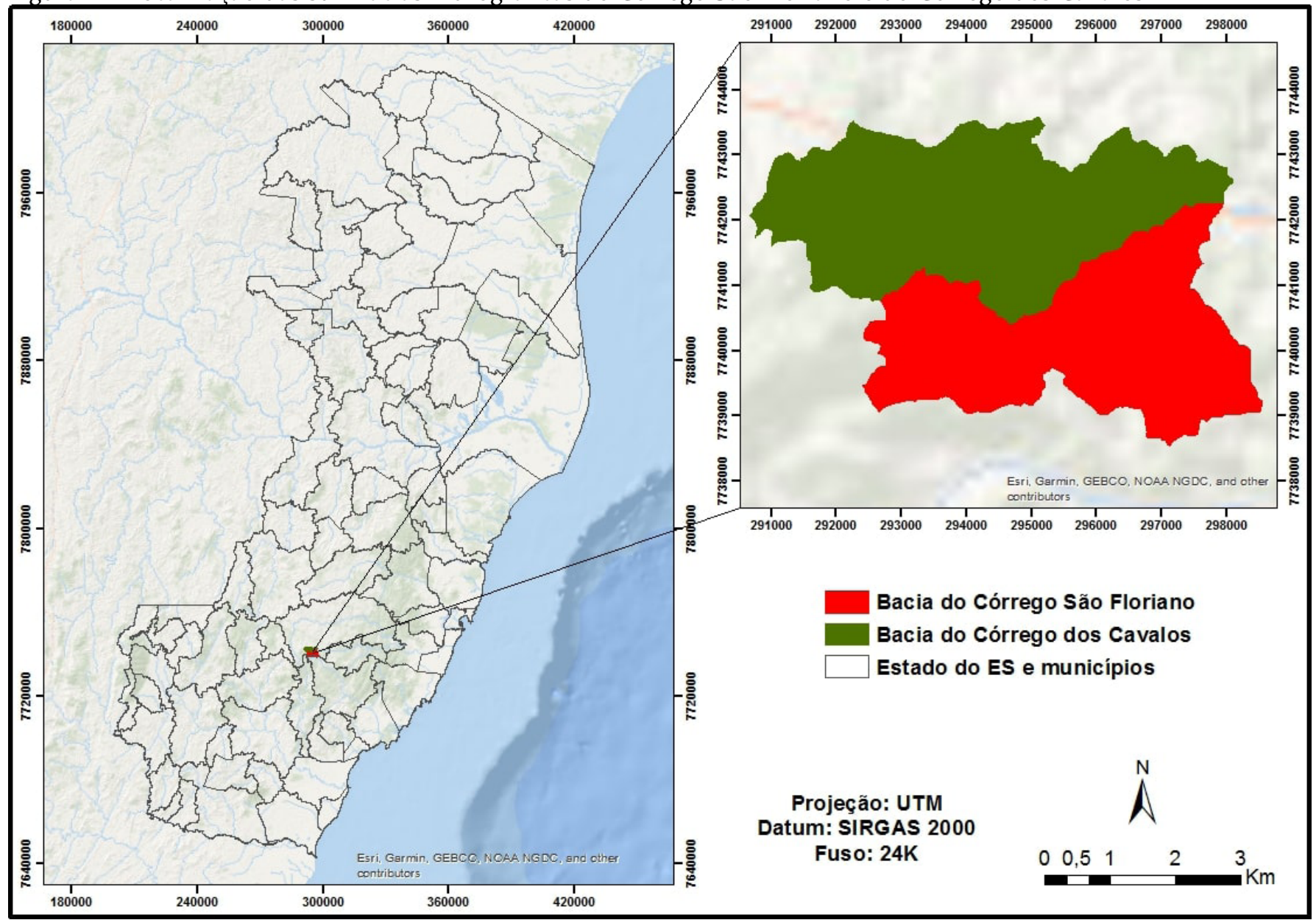

Fonte: Adaptado de GEOBASES

Foram feitos também estudos acerca do uso e ocupação de solo nas Áreas de Preservação Permanente (APP) dos cursos hídricos de cada sub-bacia hidrográfica. Com auxílio da ferramenta buffer, do ArcMap, foi delimitada a largura das APPs adotando valor igual a 30 metros, segundo as características dos cursos d'água e de acordo com o Código Florestal Brasileiro (Brasil, 2012). No início de cada fluxo d'água, foram demarcados os pontos de nascentes por meio da criação e edição de um arquivo shapefile. Na delimitação das APPs das nascentes, para cada uma delas, foi traçado um raio de 50 metros, conforme dados também consultados no Código Florestal Brasileiro (Brasil, 2012). Após a delimitação, considerando os arquivos de uso de solo adquiridos junto ao GEOBASES, foi feito um recorte através do recurso clip, delimitando, assim, o uso de solo para as Áreas de Preservação Permanente de cada bacia hidrográfica. As classes de uso do solo das APPs consideradas foram identificadas e, posteriormente, quantificadas (em percentual).

\section{Resultados e Discussão}

O mapeamento dos dados é um recurso muito considerado para tornar mais evidentes as formas de uso e ocupação dos espaços. A visualização dos fatos no espaço melhora o entendimento das interações existentes e direciona as ações necessárias, ou seja, sintetiza a realidade (Sebusiani e Bettine, 2011). A Tabela 1 apresenta a descrição e quantificação das classes de uso de solo para as bacias hidrográficas do Córrego dos Cavalos (BHCC) e do Córrego São Floriano (BHCSF) para os mapeamentos dos anos de 2007-2008 e 2012-2015. 
de Aguilar, T. O.; Fiorese, C. H. U.

Tabela 1 - Uso de solo para as sub-bacias hidrográficas do Córrego São Floriano (BHCSF) e do Córrego dos Cavalos (BHCC)

\begin{tabular}{lcccc}
\hline \multirow{2}{*}{ Classes } & \multicolumn{2}{c}{ BHCC } & \multicolumn{2}{c}{ BHCSF } \\
\cline { 2 - 5 } & $\mathbf{2 0 0 7 - 2 0 0 8 ( \% )}$ & $\mathbf{2 0 1 2 - 2 0 1 5}(\%)$ & $\mathbf{2 0 0 7 - 2 0 0 8}(\mathbf{\%})$ & $\mathbf{2 0 1 2 - 2 0 1 5}(\mathbf{\%})$ \\
\hline Afloramento rochoso & 6,38 & 6,12 & 5,37 & 4,80 \\
\hline Brejo & 0,04 & 0,06 & 0,00 & 0,00 \\
\hline Café & 0,02 & 0,02 & 0,21 & 0,16 \\
\hline Cultivos permanentes & 0,16 & 0,08 & 0,06 & 0,48 \\
\hline Cultivos temporários & 11,53 & 8,33 & 7,59 & 7,08 \\
\hline Extração mineral & 0,00 & 0,00 & 0,06 & 0,00 \\
\hline Macega & 7,55 & 9,03 & 4,91 & 5,16 \\
\hline Massa d'água & 0,12 & 0,19 & 0,11 & 0,14 \\
\hline Mata nativa & 42,43 & 42,05 & 52,61 & 52,90 \\
\hline Floresta em regeneração & 9,41 & 9,06 & 10,25 & 9,59 \\
\hline Pastagem & 11,54 & 10,74 & 8,54 & 5,01 \\
\hline Eucalipto & 6,36 & 8,61 & 6,91 & 8,91 \\
\hline Pinus & 0,00 & 0,13 & 0,61 & 0,76 \\
\hline Solo exposto & 0,36 & 0,17 & 0,34 & 0,38 \\
\hline Outros & 4,10 & 5,40 & 2,36 & 4,63 \\
\hline
\end{tabular}

Em ambas as bacias hidrográficas, há maior predominância de mata nativa, atingindo índices superiores a $40 \%$. Representa valores bons, comparado a outras bacias hidrográficas como, por exemplo, a bacia hidrográfica do Ribeirão Estrela do Norte (inferior a 13,5\%, de acordo com Fiorese e Leite (2018) e a bacia hidrográfica do rio Formiga (números inferiores a 33,1\%, segundo Leite e Rosa (2012). A BHCSF apresentou crescimento da vegetação nativa em torno de $0,3 \%$, porém, a BHCC apresentou uma redução dessa mesma classe com um percentual também muito próximo de $0,3 \%$. Rodrigues et al. (2004) atribuem à redução de florestas nativas à expansão da fronteira agrícola, causando danos irreparáveis à biodiversidade e também ao ser humano. Fato este que pode ser evidenciado na BHCC, atribuído não somente à agricultura, como também pelo crescimento de outras formas de uso dos solos locais.

Quando somadas as áreas de mata nativa das duas bacias para os anos 2007-2008 e 2012-2015, os valores permanecem estáveis, com queda inferior a $0,1 \%$, ou seja, pode-se afirmar que praticamente não houve redução nem aumento dessa classe, sendo um fator positivo para o contexto da macrobacia hidrográfica, pois a manutenção e o equilíbrio de um ecossistema saudável culminam em qualidade de vida para os organismos presentes (Rodrigues et al., 2004), além de vários benefícios para solo, água e ar. Mas, há maior preocupação com a qualidade ambiental da sub-bacia do Córrego dos Cavalos que, mesmo não apresentando predominância do processo de urbanização, apresentou queda nos índices de vegetação nativa e em estágio de regeneração. Thomaz (2010) afirma que a Mata Atlântica, bioma que abrange as duas sub-bacias hidrográficas estudadas, vem sofrendo forte degradação, sendo considerado um dos biomas mais ameaçados do país. Por isso, a devastação dessa formação florestal é preocupante quando se analisa o contexto de microbacia, como a do BHCC.

As áreas de macega aumentaram significativamente na BHCC e na BHCSF. Os percentuais de área estimados para essa classe foram superiores à de outras bacias hidrográficas, como a bacia do ribeirão Estrela do Norte (Fiorese e Leite, 2018). Esse fato indica que há problemas quanto ao manejo do uso de solo, principalmente na sub-bacia do Córrego dos Cavalos, pois as áreas de macega poderiam ser aproveitadas para outras finalidades, como, por exemplo, na restauração florestal ou, até mesmo, na implantação de agroflorestas, aumentando, assim, a biodiversidade animal e vegetal e melhorando a qualidade ambiental dessas áreas. Os sistemas agroflorestais, de acordo com Schembergue et al. (2017), têm potencial de aumentar a lucratividade agrícola das propriedades, além de tornar a produção mais sustentável e proporcionar ganhos ambientais.

A pastagem, classe predominante em outras bacias hidrográficas, apresentou índices considerados baixos. Na BHCSF, houve uma redução drástica, ao passo que na BHCC, a redução foi menor, o que pode ser atribuído ao 
Uso e ocupação do solo de duas sub-bacias hidrográficas no município de Domingos Martins, estado do Espírito Santo

crescimento de outras classes, como o eucalipto. De Zen et al. (2008) destacam impactos ambientais decorrentes da pecuária, caracterizada por ser extensiva, no Brasil, que são: destruição de ecossistemas naturais, compactação e erosão do solo e poluição dos recursos hídricos. Impactos estes que não são muito agravantes no que diz respeito a áreas de pasto em ambas as bacias hidrográficas, porém, é importante destacar o manejo correto da pecuária para maior sustentabilidade desse segmento econômico.

O cultivo de café, destaque em bacias hidrográficas, como a sub-bacia hidrográfica do ribeirão Estrela do Norte (Fiorese e Leite, 2018), apresentou índices extremamente baixos (inferiores a $0,5 \%$ ). No tocante à qualidade ambiental, é um fator positivo, considerando os impactos ambientais negativos que a cafeicultura proporciona quando manejada indevidamente como, por exemplo, danos aos recursos hídricos e ao solo devido ao uso de agrotóxicos e fertilizantes e desequilíbrio ambiental atrelado ao aparecimento de pragas e doenças danosas às lavouras, além de prejuízos à biodiversidade (Lopes et al., 2014). Na região, destacam-se os chamados cultivos temporários, apesar de ter havido redução considerável das áreas na BHCSF. Assim como a cafeicultura, esses cultivos precisam de um correto manejo, pois a retirada de vegetação nativa para o plantio de culturas proporciona várias alterações no solo, sobretudo no que diz respeito à redução da matéria orgânica e de nutrientes (Nunes et al., 2009).
A silvicultura do eucalipto vem ganhando destaque nas duas bacias hidrográficas, atingindo índices superiores a $8,5 \%$. As chamadas florestas plantadas, incluindo o eucalipto, passaram a suprir de maneira crescente a demanda da indústria da celulose e do papel, além de áreas importantes como a siderurgia e secagem de grãos (Moreira et al., 2017). Os impactos benéficos desse ramo da silvicultura são relacionados ao aumento de emprego, renda, constituindo benefícios socioeconômicos (Moledo et al., 2016). Porém, De Vechi e Magalhães Junior (2018) alertam para os impactos ambientais provocados pela eucaliptocultura como, por exemplo, alteração da qualidade da água devido à presença de substâncias químicas presentes nas folhas do vegetal quando levadas para um curso hídrico, evitar a ocorrência de biodiversidade por ser uma espécie dominante e exótica e grande consumo de água. Assim como as demais culturas, o eucalipto precisa de um manejo correto para haver maior produtividade atrelada à minimização de danos ambientais.

Outra classe com boa representatividade é a formação rochosa, com índices próximos a 5\%. As demais classes (brejo, pinus, extração mineral, solo exposto) apresentaram percentual muito baixo e, portanto, não foram discutidos com grande veemência neste trabalho. Nas Figuras 2 a 5 estão apresentados, respectivamente, a distribuição das classes de uso e ocupação das terras para as bacias hidrográficas do Córrego dos Cavalos e do Córrego São Floriano, nos mapeamentos considerados.

Figura 2 - Uso de solo para a sub-bacia hidrográfica do Córrego dos Cavalos no mapeamento dos anos 2007-2008

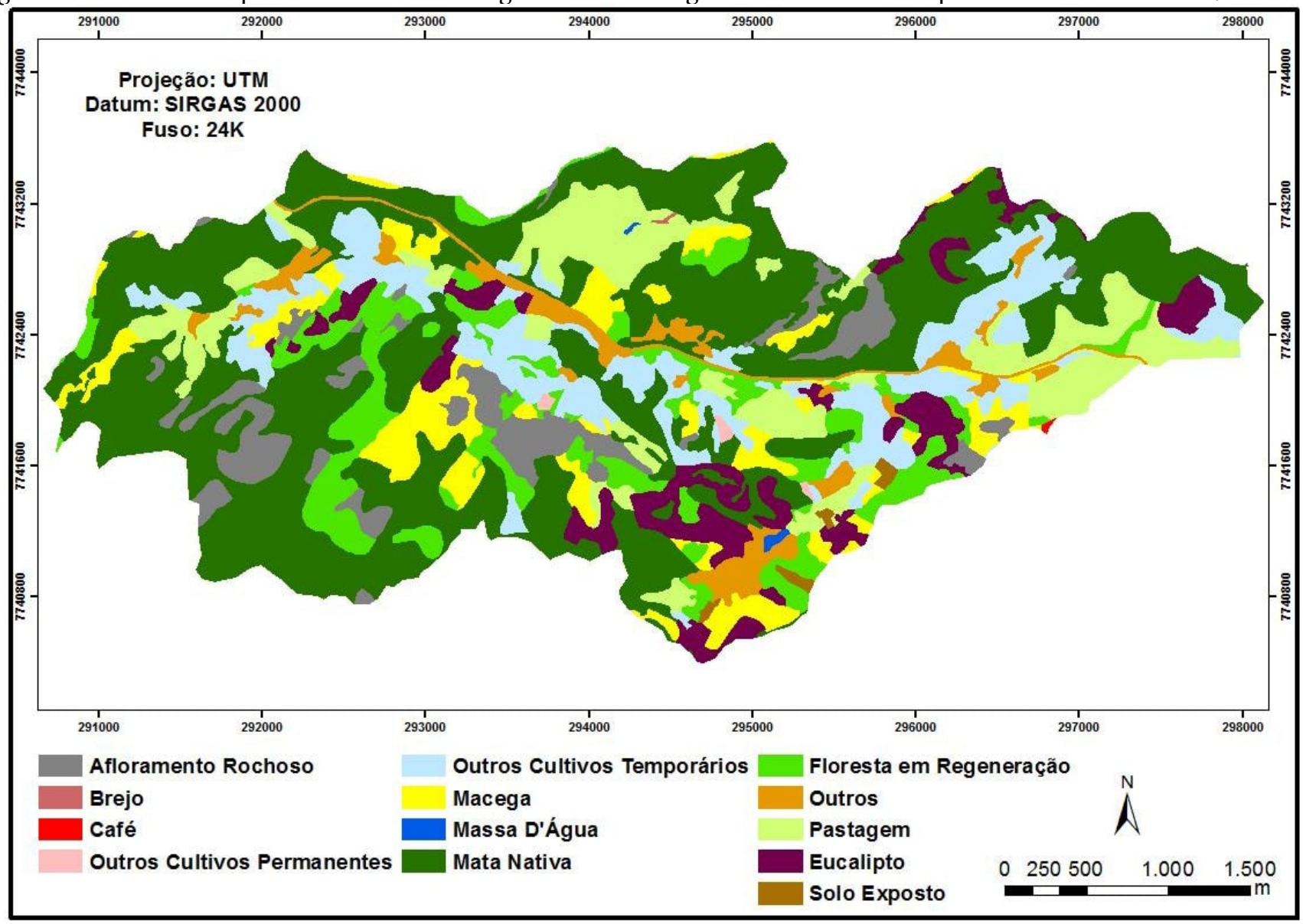

Cad. Ciênc. Agrá., v. 11, p. 01-10, 2019. e-ISSN: 2447-6218 / ISSN: 1984-6738 
de Aguilar, T. O.; Fiorese, C. H. U.

Figura 3 - Uso de solo para a sub-bacia hidrográfica do Córrego dos Cavalos no mapeamento dos anos 2012-2015

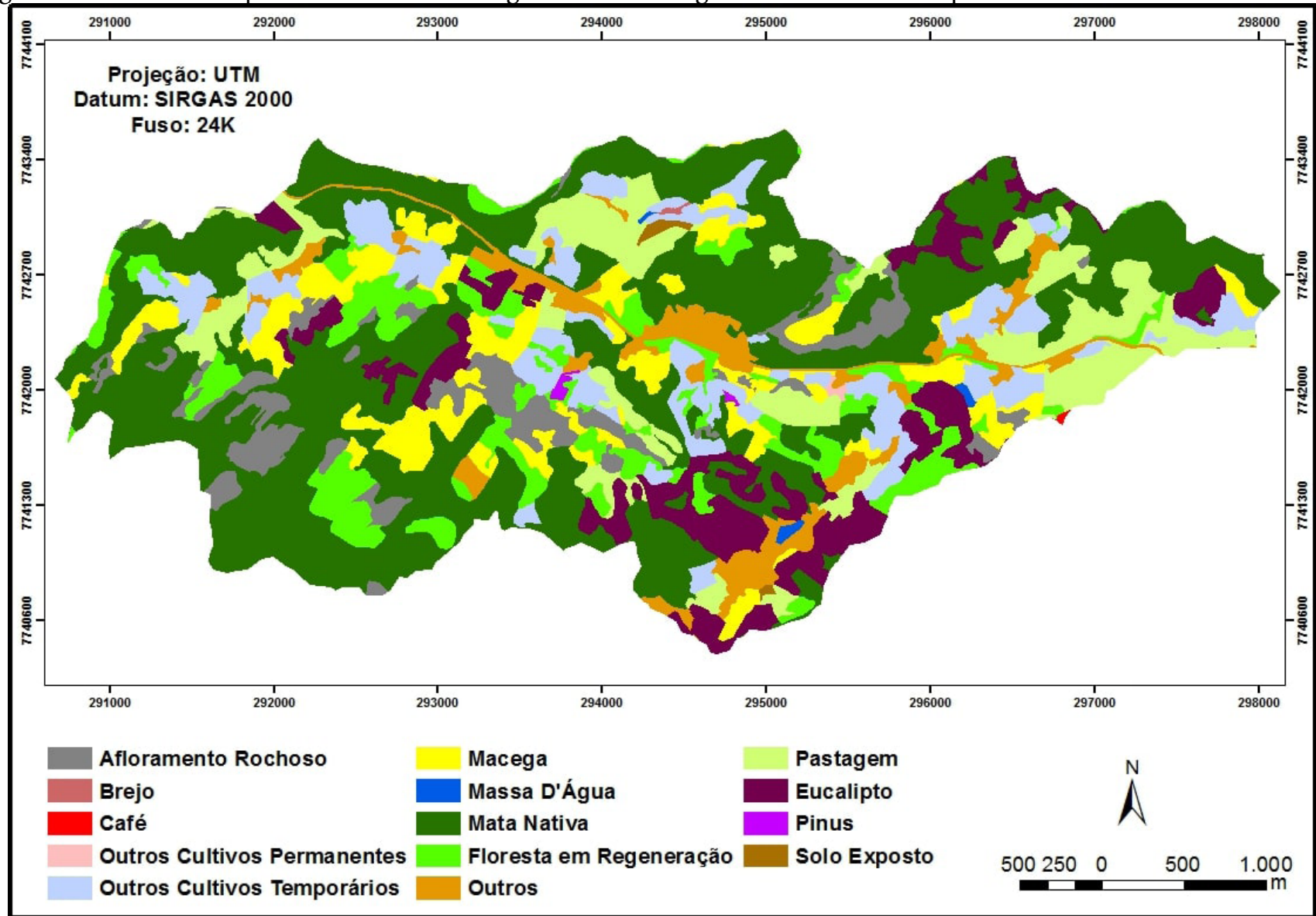

Figura 4 - Uso de solo para a sub-bacia hidrográfica do Córrego São Floriano no mapeamento dos anos 2007-2008

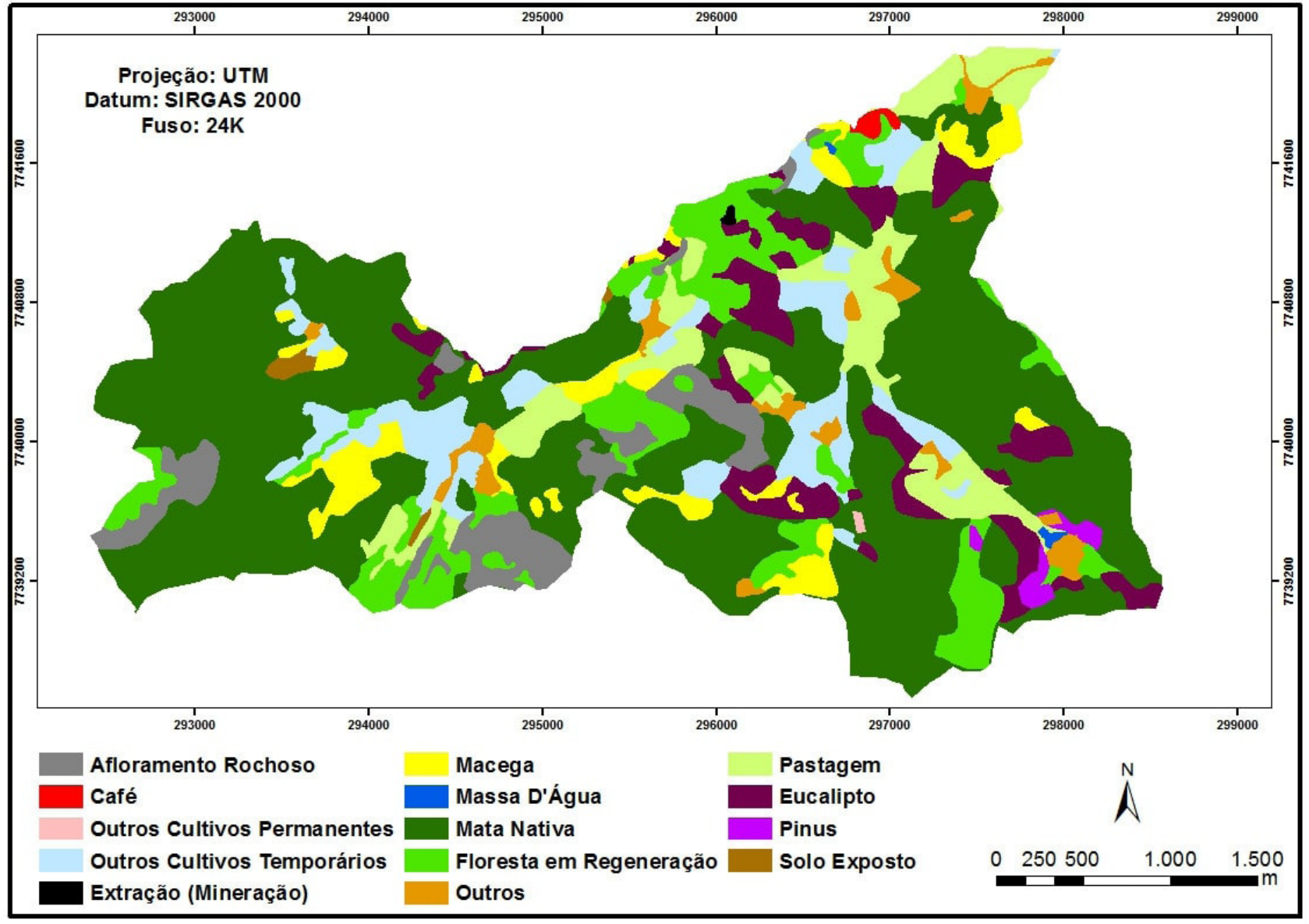

Cad. Ciênc. Agrá., v. 11, p. 01-10, 2019. e-ISSN: 2447-6218 / ISSN: 1984-6738 
Uso e ocupação do solo de duas sub-bacias hidrográficas no município de Domingos Martins, estado do Espírito Santo

Figura 5 - Uso de solo para a sub-bacia hidrográfica do Córrego São Floriano no mapeamento dos anos 2012-2015

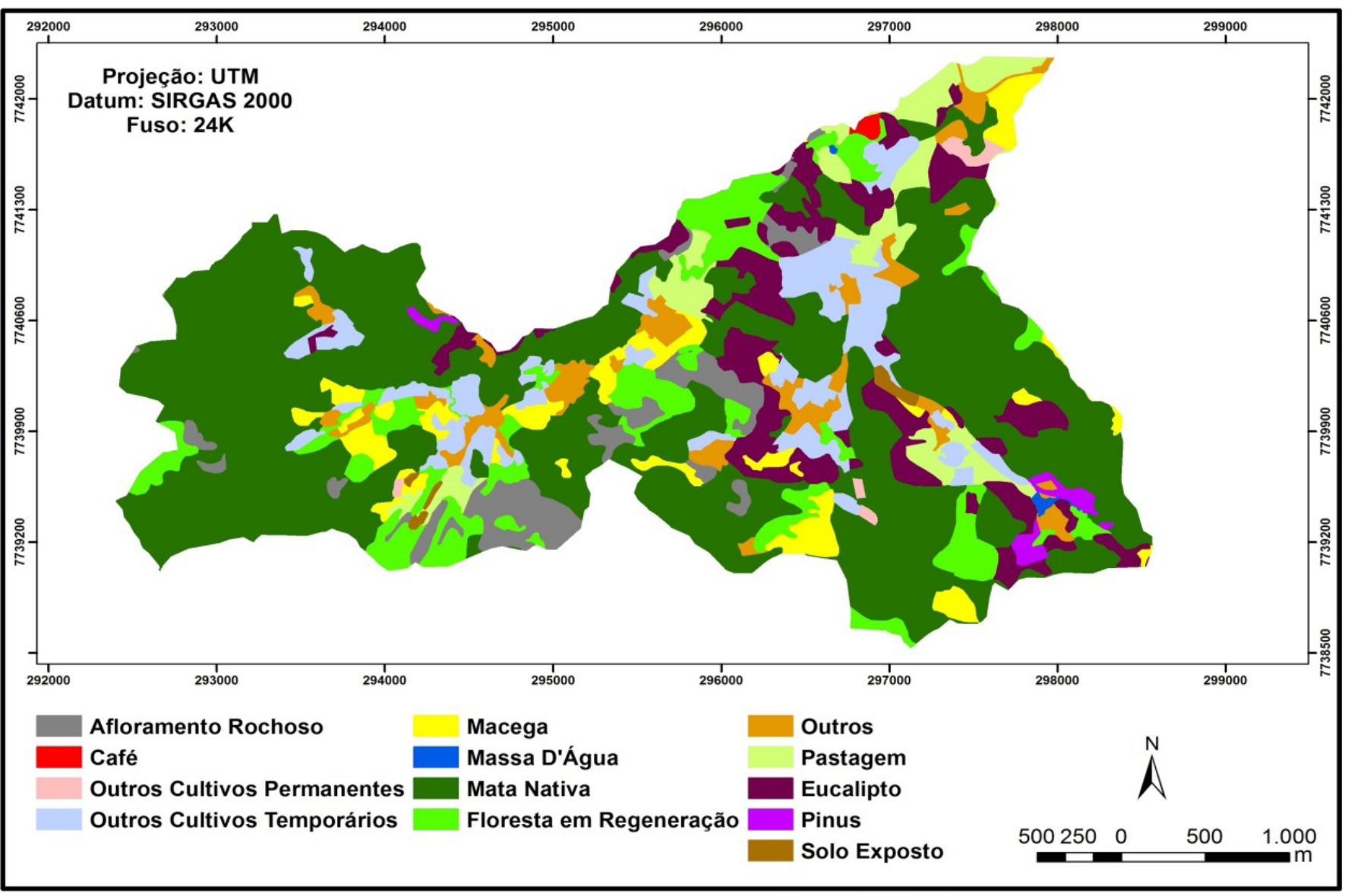

Na BHCC, houve um aumento considerável do cultivo de eucalipto, atrelado à redução de áreas de mata nativa que, por sua vez, estão mais concentradas próximas ao limite da referida bacia, exceto na parte leste e sudeste. A sustentabilidade não é sinônimo exclusivo de proteção à natureza, mas também da produção. O uso sustentável pode ser a maior garantia para um sistema continuar, contrapondo a exclusiva proteção da natureza, além de manter a dimensão econômica para o desenvolvimento sustentável (Andrae et al., 2018). Por isso, na BHCC, a redução da vegetação nativa precisa estar associada a uma produção mais limpa e rentável, visto que os crescimentos de cultivos temporários e da eucaliptocultura, quando manejados de forma incorreta, acarretam impactos ambientais negativos que podem interferir, por exemplo, na disponibilidade de água para abastecimento humano. Além disso, as áreas de macega estavam um tanto fragmentadas e, muitas delas, próximas a florestas nativas e em regeneração. Dessa forma, ações do poder público em relação a essa situação se fazem necessárias para um melhor aproveitamento dessas áreas.

Na BHCSF, houve um nítido aumento da vegetação nativa, contrapondo a outra bacia hidrográfica estudada. Esse fato pode ser atribuído a programas de reflorestamento ambiental, como o Reflorestar, segundo o
Instituto Estadual de Meio Ambiente e Recursos Hídricos (Iema, 2019), além da influência do Comitê da Bacia Hidrográfica do Rio Jucu, mostrando, assim, que ações para o aumento da cobertura florestal estão sendo implantadas corretamente nesta região. Contudo, o crescimento do eucalipto na BHCSF se constitui numa preocupação, principalmente estando em forma de monocultivos, devido aos impactos ambientais que essa cultura proporciona. Apesar disso, o aumento das áreas de vegetação nativa foi largamente maior que o crescimento do eucalipto, aferindo, assim, um bom manejo do uso de solo nesta região.

Em ambas as bacias hidrográficas, não houve uma fragmentação excessiva da mata nativa, ou seja, a mesma ocupa áreas de maneira mais uniforme. Isso significa maiores benefícios ambientais, pois, de acordo com Silva et al. (2013), a fragmentação é consequência da exploração e depredação antrópica sobre os recursos naturais provocando, assim, danos à fauna e flora. Fato este que não é um agravante em ambas as bacias estudadas, pois muitos locais com vegetação nativa estão aglomerados. A Tabela 2 mostra o percentual de uso de solo para as sub-bacias hidrográficas do Córrego dos Cavalos e do Córrego São Floriano, nos anos 2007-2008 e 2012-2015. 
de Aguilar, T. O.; Fiorese, C. H. U.

Tabela 2 - Uso de solo para as Áreas de Preservação Permanentes das duas sub-bacias nos mapeamentos considerados

\begin{tabular}{lcccc}
\hline \multirow{2}{*}{ Classes } & \multicolumn{2}{c}{ BHCC $^{\mathbf{1}}$} & \multicolumn{2}{c}{ BHCSF $^{2}$} \\
\cline { 2 - 5 } & $\mathbf{2 0 0 7 - 2 0 0 8}(\%)$ & $\mathbf{2 0 1 2 - 2 0 1 5}(\%)$ & $\mathbf{2 0 0 7 - 2 0 0 8 ~ ( \% )}$ & 2012-2015 (\%) \\
\hline Afloramento rochoso & 2,44 & 2,19 & 0,86 & 0,64 \\
\hline Brejo & 0,14 & 0,23 & 0,00 & 0,00 \\
\hline Cultivos permanentes & 0,00 & 0,08 & 0,04 & 0,08 \\
\hline Cultivos temporários & 12,69 & 11,12 & 11,28 & 11,94 \\
\hline Macega & 7,02 & 6,96 & 4,67 & 4,73 \\
\hline Massa d'água & 0,56 & 0,59 & 0,52 & 0,72 \\
\hline Mata nativa & 35,79 & 33,83 & 44,29 & 43,95 \\
\hline Floresta em regeneração & 11,31 & 13,34 & 13,32 & 13,01 \\
\hline Pastagem & 15,74 & 13,45 & 16,08 & 9,01 \\
\hline Eucalipto & 2,51 & 3,28 & 2,42 & 3,71 \\
\hline Pinus & 0,00 & 0,19 & 0,92 & 0,91 \\
\hline Solo exposto & 0,17 & 0,01 & 0,36 & 0,88 \\
\hline Outros & 11,62 & 14,71 & 5,25 & 10,42 \\
\hline
\end{tabular}

${ }^{1}$ BHCC $=$ sub-bacia do Córrego dos Cavalos

${ }^{2}$ BHCSF $=$ sub-bacia do Córrego São Floriano

Em ambas as bacias hidrográficas, houve redução da vegetação nativa, constituindo um motivo de preocupação no que tange a qualidade e quantidade dos recursos hídricos. As APPs, segundo Soares et al. (2017), proporcionam a sobrevivência de corpos d'água, bem como a manutenção da biodiversidade local, sendo de grande a manutenção de sua vegetação. No entanto, os mesmos autores alertam que a falta de políticas públicas e planejamento ambiental resultam na degradação destes ambientes. Como exemplos, podem ser citados: assoreamento dos cursos hídricos, erosão dos solos e aumento do escoamento superficial em detrimento ao subterrâneo. Fatos estes que podem trazer prejuízos à qualidade ambiental próximas aos cursos hídricos das referidas bacias.

Contudo, é importante ressaltar que os índices de mata nativa foram superiores à APPs de outras bacias hidrográficas, como a estudada por Fiorese e Leite (2018), que apresentou valores inferiores a $13,5 \%$. Portanto, os percentuais de floresta nativa na BHCC e na BHCSF são considerados bons em comparação com outras bacias, mesmo com a sua redução no período considerado, sendo este o fator preocupante nas APPs locais. Além disso, a redução da pastagem, sobretudo na APP da sub-bacia do Córrego São Floriano, indica um fenômeno positivo perante a qualidade ambiental, sabendo-se dos riscos que as pastagens provocam quando manejadas incorretamente e associadas a cursos hídricos. Alguns dos danos são: assoreamento de mananciais, danos à qualidade da água, aumento do escoamento pluvial e intensificação de processos erosivos.
As áreas de macega, que representaram pouco mais de $4 \%$, indicaram que existem problemas de manejo do uso de solo nas APPs no tocante a essa classe. No entanto, a pecuária (pastagem) nas APPs diminuiu, ao passo que o cultivo de eucalipto aumentou. Ribeiro et al. (2014) ressaltam a identificação, em vários estudos, de conflitos entre APPs e uso e ocupação de terras, fato que pode ser percebido nas Áreas de Preservação Permanente nas bacias hidrográficas estudadas.

A predominância de cultivos temporários nas APPs também é evidente, o que também significa riscos à sustentabilidade do ambiente natural como, por exemplo, uso de agroquímicos nas lavouras e a consequente lixiviação das substâncias ali presentes, além de danos à biodiversidade terrestre e aquática e degradação do solo. Portanto, esses cultivos necessitam de um manejo adequado, e poderiam estar associados a uma agrofloresta, por exemplo. Trazendo, assim, vários ganhos ambientais e econômicos. Carmo (2015) destaca fatores que interferem na variação e implantação dos cultivos temporários como, por exemplo, a terra e sua influência, duração dos ciclos produtivos, trabalho demandado por cada cultura, dependência climática e a heterogeneidade da produção. Já as APPs constituem aproximadamente $16,75 \%$ da BHCSF e $16,21 \%$ da BHCC, enfatizando a necessidade de ações prioritárias nessas áreas quanto à preservação da qualidade do meio natural. 
Uso e ocupação do solo de duas sub-bacias hidrográficas no município de Domingos Martins, estado do Espírito Santo

\section{Conclusão}

Os valores de vegetação nativa foram considerados excepcionais para ambas as bacias hidrográficas, além de não estarem fragmentadas na maior parte, porém, apresentaram redução na BHCC. As áreas de cafeicultura e pastagem representaram percentual baixo, sendo um fator positivo quanto à manutenção da qualidade biótica e abiótica. A silvicultura (eucalipto e pinus) apresentou crescimento no período considerado, principalmente em relação ao eucalipto. Cultivos temporários também têm destaque em ambas as bacias hidrográficas, mas, assim como as demais culturas, necessitam de cuidados. A representatividade da macega é um fator preocupante quanto ao planejamento correto do uso e ocupação de solos.
Nas APPs, a redução da mata nativa foi o maior problema visto, contudo, a queda nas áreas de pastagem, mesmo com o aumento da silvicultura e a predominância de cultivos temporários, indica que o meio físico (solo e água) provavelmente tenha melhorado. Medidas podem ser propostas para melhorar a qualidade ambiental de ambas as sub-bacias, tais como: implantação de sistemas agroflorestais em monocultivos temporários e em áreas de macega, manejo correto da pastagem e das silviculturas do pinus e eucalipto (trazendo benefícios, como o controle da erosão dos solos locais, minimização do assoreamento dos córregos e maior rentabilidade aos produtores locais) e trabalhos de educação ambiental com os produtores rurais da região, a fim de orientá-los sobre os métodos de conservação ambiental e sua importância no nível de cada sub-bacia hidrográfica.

\section{Referências}

Alvares, C. A.; Stape, J. L.; Sentelhas, P. C.; Gonçalves, J. L. M.; Sparovek, G. 2013. Köppen's climate classification map for Brazil. Meteorologische Zeitschrift, 22: 711-728. Doi: https://dx.doi.org/10.1127/09412948/2013/0507.

Andrae, F. H.; Schneider, P. R.; Durlo, M. A. 2018. Importância do manejo de florestas nativas para a renda da propriedade e abastecimento do mercado madeireiro. Ciência Florestal, 28: 1293-1302. Doi: http:// dx.doi.org/10.5902/1980509832579.

Brasil. 2012. Lei no 12.651 , de 25 de maio de 2012. Dispõe sobre a proteção da vegetação nativa e dá outras providências. Brasília, DF. Disponível em : http://www.planalto.gov.br/ccivil_03/_Ato20112014/2012/Lei/L12651.htm.

Carmo, C. R. S. 2015. Culturas temporárias no Brasil: um estudo sobre possíveis determinantes da área cultivada ao longo dos anos 1991 a 2012. Revista Getec, 4: 55-78. Disponível em: http://www.fucamp. edu.br/editora/index.php/getec/article/view/569.

Chuerubim, M. L.; Pavanin, E. V. Análise do uso e ocupação do solo na bacia hidrográfica do córrego Barbosa no ano de 2011. 2013. Revista GEOUSP, 33: 229-238. Doi: https://doi.org/10.11606/issn.2179-0892. geousp.2013.74313.

Coelho, V. H. R.; Montenegro, S. M. G. L.; Almeida, C. N.; Lima, E. R. V.; Ribeiro Neto, A.; Moura, G. S. S.. 2014. Dinâmica do uso e ocupação do solo em uma bacia hidrográfica do semiárido brasileiro. Revista Brasileira de Engenharia Agrícola e Ambiental, 18: 64-72. Doi: http:// dx.doi.org/10.1590/S1415-43662014000100009.

Cornelli, R.; Schneider, V. E.; Bortolin, T. A.; Cemin, G.; Santos G. M. 2016. Análise da influência do uso e ocupação do solo na qualidade da água de duas sub-bacias hidrográficas do município de Caxias do Sul. Scientia cum Industria, 4: 1-14. Doi: http://dx.doi. org/10.18226/23185279.v4iss1p1.

Criado, R. C.; Piroli, E. L. 2012. Geoprocessamento como ferramenta para a análise do uso da terra em bacias hidrográficas. Revista Geonorte, 3: $1010-1021$.

De Zen, S.; Barioni, L. G.; Bonato, D. B. B.; Almeida, M. H. S. P.; Rittl, T. F. 2008. Pecuária de corte brasileira: impactos ambientais e emissões de gases efeito estufa (GEE). Universidade de São Paulo. Piracicaba.
Fiorese, C. H. U.; Leite, V. R. 2018. Dinâmica do uso e cobertura do solo na sub-bacia hidrográfica do ribeirão Estrela do Norte no município de Castelo, estado do Espírito Santo. Agrarian Academy, 5: 52-65. Doi: 10.18677/Agrarian_Academy_2018B6. Disponível em http://www. conhecer.org.br/Agrarian\%20Academy/2018B/dinamica.pdf.

Iema. 2019. Programa Reflorestar. Disponível em: https://iema.es.gov. br/programa-reflorestar.

Leal, A. C. 2012. Planejamento ambiental de bacias hidrográficas como instrumento para o gerenciamento de recursos hídricos. Revista Entre-Lugar, 6:65-84. http://ojs.ufgd.edu.br/index.php/entre-lugar/ article/view/2447.

Leite, E. F; Rosa, R. 2012. Análise do uso, ocupação e cobertura da terra na bacia hidrográfica do rio Formiga, Tocantins. Revista Eletrônica de Geografia, 14: 90-106. Disponível em: http://www.observatorium. ig.ufu.br/pdfs/4edicao/n12/05.pdf.

Lopes, P. R.; Araújo, K. C. S.; Lopes, I. M.; Rangel, R. P.; Santos, N. F. F; Kageyama, F. Y. 2014. Uma análise das consequências da cafeicultura convencional e das opções de modelos sustentáveis de produção agricultura orgânica e agroflorestal. Revista Espaço de Diálogo e Desconexão, 8: 1-38. Doi: https://doi.org/10.32760/1984-1736/ REDD/2014.v8i2.6912.

Lopes, S. M. F.; Cabral, J. B. P.; Braga, C. C.; Ramalho, F. L. 2016. Avaliação espaço-temporal do uso da terra nas bacias hidrográficas do ribeirão Paraíso-GO e córrego Cerrado/Cadunga-MG. Revista Geoambiente On-Line, 27: 114-136. Doi: https://doi.org/10.5216/ revgeoamb.v0i27.44758.

Menezes, J. P. C.; Bittencourt, R. P.; Farias, M. S.; Bello, I. P; Fia, R; Oliveira, R. F.C. 2016. Relação entre padrões de uso e ocupação do solo e qualidade da água em uma bacia hidrográfica urbana. Engenharia Sanitária e Ambiental, 21: 519-534. Doi: http://dx.doi.org/10.1590/ S1413-41522016145405.

Moledo, J. C.; Saad, A. R.; Dalmas, F. B.; Arruda, R. O. M.; Casado, F. 2016. Impactos ambientais relativos à silvicultura de eucalipto: uma análise comparativa do desenvolvimento e aplicação no plano de manejo florestal. Geociências, 35: 512-530. Disponível em: http://ppegeo.igc. usp.br/index.php/GEOSP/article/view/9968.

Moraes, G. F.; Lima, E. B. N. R.; Ferrarez, E. M. 2018. Caracterização fisiográfica e do uso e ocupação do solo nas microbacias urbanas da cidade de Cuiabá-MT. Engineering and Science, 7: 42-53. Doi: http:// dx.doi.org/10.18607/ES201876822. 
Moreira, J. M. M. A. P.; Simioni, F. J.; Oliveira, E. B. 2017. Importância e desempenho das florestas plantadas no contexto do agronegócio brasileiro. Floresta, 47: 85-94. Doi: http://dx.doi.org/10.5380/ rf.v47i1.47687.

Nunes, L. A. P. L.; Dias, L. E.; Jucksch, I.; Barros, N. F.; Kasuya, M. C. M.; Correia, M. E. F. Impacto do monocultivo de café sobre os indicadores biológicos do solo na zona da mata mineira. Ciencia Rural, 39: 2467 2474. Doi: http://dx.doi.org/10.1590/S0103-84782009005000216.

Pessoa, S. P. M.; Galvanin, E. A. S.; Neves, S. M. A. S.; Kreitlow, J. P. 2013. Análise espaço-temporal do uso e cobertura da terra na bacia hidrográfica do rio do Bugres - Mato Grosso, Brasil. Enciclopédia Biosfera, 9: 162174. Doi: http://dx.doi.org/10.1590/S0100-67622013000100013.

Ribeiro, C. A. A. S.; Lemos, N. C. M.; Barros, K. O.; Soares, V. P.; Silva, E.; Menezes, S. J. M. S. 2014.Uso e a ocupação da terra em áreas de preservação permanente da bacia hidrográfica do Córrego Sertão, Cajuri, MG. Agrogeoambiental, 6: 1-9. Doi: http://dx.doi.org/10.18406/2316$1817 \mathrm{v} 6 \mathrm{n} 22014635$.

Rodrigues, E. R.; Moscogliato, A. V.; Nogueira, A. C. 2004. Viveiros "agroflorestais" em assentamentos de reforma agrária como instrumentos de recuperação ambiental: um estudo de caso no Pontal do Paranapanema. Caderno de Biodiversidade, 4: 1-8. Disponível em: http://www.iap.pr.gov.br/arquivos/File/artigo_1.pdf.
Schembergue, A.; Cunha, D. A.; Carlos, S. M.; Pires, M. V.; Faria, R. M. 2017. Sistemas agroflorestais como estratégia de adaptação aos desafios das mudanças climáticas no Brasil. Revista de Economia e Sociologia Rural, 55: 9-30. Doi: http://dx.doi.org/10.1590/123456781806-94790550101.

Sebusiani, H. R. V.; Bettine, S. C. 2011. Metodologia de análise de uso e ocupação do solo em micro bacia urbana. Revista Brasileira de Gestão e Desenvolvimento Regional, 7: 256-285. Disponível em: https://www. rbgdr.net/revista/index.php/rbgdr/article/view/366.

Silva, A.; Musa, C. I.; Renner, S.; Horn, T. B.; Rempel, C., Ferla, N. J. 2013. A influência do efeito de borda na abundância e diversidade de epífitas no Jardim Botânico de Lajeado, Rio Grande do Sul. Destaques Acadêmicos, 5: 75-88. Disponível em: http://www.univates.br/revistas/ index.php/destaques/article/view/283.

Soares, N. G.; Vagetti, A. B. N.; Beraldi, A. L. P. G. 2017. Degradação ambiental nas áreas de preservação permanente do córrego Marinheirinho: uma proposta de educação ambiental. Unifev: Ciência e Tecnologia, 3: 99-112.

Thomaz, L. D. 2010. A Mata Atlântica no estado do Espírito Santo, Brasil: de Vasco Fernandes Coutinho ao século 21. Boletim do Museu de Biologia "Melo Leitão", 27:5-20. Disponível em: http://boletim. sambio.org.br/pdf/27_01.pdf. 